\title{
Retinal vascular tortuosity in schizophrenia and bipolar disorder
}

Citation for published version (APA):

Appaji, A., Nagendra, B., Chako, D. M., Padmanabha, A., Jacob, A., Hiremath, C., Varambally, S.,

Kesavan, M., Venkatasubramanian, G., Rao, S. V., Webers, C. A. B., Berendschot, T. T. J. M., \& Rao, N. P. (2019). Retinal vascular tortuosity in schizophrenia and bipolar disorder. Schizophrenia Research, 212, 26-32. https://doi.org/10.1016/j.schres.2019.08.020

Document status and date:

Published: 01/10/2019

DOI:

10.1016/j.schres.2019.08.020

Document Version:

Publisher's PDF, also known as Version of record

Document license:

Taverne

Please check the document version of this publication:

- A submitted manuscript is the version of the article upon submission and before peer-review. There can be important differences between the submitted version and the official published version of record.

People interested in the research are advised to contact the author for the final version of the publication, or visit the DOI to the publisher's website.

- The final author version and the galley proof are versions of the publication after peer review.

- The final published version features the final layout of the paper including the volume, issue and page numbers.

Link to publication

\footnotetext{
General rights rights.

- You may freely distribute the URL identifying the publication in the public portal. please follow below link for the End User Agreement:

www.umlib.nl/taverne-license

Take down policy

If you believe that this document breaches copyright please contact us at:

repository@maastrichtuniversity.nl

providing details and we will investigate your claim.
}

Copyright and moral rights for the publications made accessible in the public portal are retained by the authors and/or other copyright owners and it is a condition of accessing publications that users recognise and abide by the legal requirements associated with these

- Users may download and print one copy of any publication from the public portal for the purpose of private study or research.

- You may not further distribute the material or use it for any profit-making activity or commercial gain

If the publication is distributed under the terms of Article $25 \mathrm{fa}$ of the Dutch Copyright Act, indicated by the "Taverne" license above, 


\title{
Retinal vascular tortuosity in schizophrenia and bipolar disorder
}

\author{
Abhishek Appaji a, c, 1 , Bhargavi Nagendra b, ${ }^{1}$, Dona Maria Chako ${ }^{\mathrm{b}}$, Ananth Padmanabha ${ }^{\mathrm{a}}$, \\ Arpitha Jacob b , Chaitra V. Hiremath ${ }^{\mathrm{b}}$, Shivarama Varambally ${ }^{\mathrm{b}}$, Muralidharan Kesavan ${ }^{\mathrm{b}}$, \\ Ganesan Venkatasubramanian ${ }^{b}$, Shyam Vasudeva Rao ${ }^{a, c}$, Carroll A.B. Webers ${ }^{c}$, \\ Tos T.J.M. Berendschot ${ }^{\text {c }}$, Naren P. Rao ${ }^{\text {b, * }}$
}

${ }^{a}$ Department of Medical Electronics, B.M.S. College of Engineering, Bangalore, India

${ }^{\mathrm{b}}$ Dept. of Psychiatry, National Institute of Mental Health and Neurosciences, Bangalore, India

${ }^{\mathrm{c}}$ University Eye Clinic Maastricht, Maastricht University, Maastricht, the Netherlands

\section{A R T I C L E I N F O}

\section{Article history:}

Received 2 January 2019

Received in revised form

23 April 2019

Accepted 18 August 2019

Available online 26 August 2019

Keywords:

Retinal vascular tortuosity

Fundus

Schizophrenia

Bipolar disorder

Psychoses

Cerebrovascular

\begin{abstract}
A B S T R A C T
The micro-vasculature of retina and brain share common morphological, physiological, and pathological properties. Retina being easily accessible, retinal vascular examination provides an indirect assessment of cerebral vasculature. Considering the high prevalence of vascular morbidity in SCZ and BD a few studies have examined retinal vascular caliber and have reported increased retinal venular caliber in schizophrenia (SCZ). Retinal vascular tortuosity could serve as a better structural measure than caliber as it is static and less susceptible to pulse period variations. However, to date, no study has examined retinal vascular tortuosity in SCZ and bipolar disorder (BD). Hence, we examined retinal vascular tortuosity in comparison with healthy volunteers (HV). We included 255 subjects ( $78 \mathrm{HV}, 79 \mathrm{SCZ}$, and $86 \mathrm{BD}$ ) in the age range of 18 to 50 years. Trained personnel acquired images using a non-mydriatic fundus camera. To measure the average retinal arteriolar tortuosity index (RATI) and retinal venular tortuosity index (RVTI), we used a previously validated, semi-automatic algorithm. The results showed significant differences across the three groups in RATI but not in RVTI; both BD and SCZ had significantly increased RATI compared to HV. There was also a significant difference between SCZ and BD, with BD having higher RATI. If shown to be of predictive utility in future longitudinal studies, it has the potential to identify patients at risk of development of adverse vascular events. As retinal vascular imaging is non-invasive and inexpensive, it could serve as a proxy marker and window to cerebral vasculature.
\end{abstract}

() 2019 Elsevier B.V. All rights reserved.

\section{Introduction}

Retinal small vessels share common embryologic origins and have similar anatomical and physiological properties with cerebral small vessels, thus providing a unique "window" to study cerebrovascular disease (Patton et al., 2005; Wong et al., 2001). Several studies have demonstrated a link between presence of retinal microvascular abnormalities and clinical (e.g., stroke, dementia) and subclinical (white matter lesions on magnetic resonance imaging) cerebrovascular disease (Cheung et al., 2010; de Jong et al., 2011; Kim et al., 2011; Lesage et al., 2009; Wong et al., 2002). Considering the increased prevalence of vascular abnormalities and higher incidence of adverse cerebro/cardiovascular events in

\footnotetext{
* Corresponding author at: Department of Psychiatry, National Institute of Mental Health and Neurosciences, Bangalore, India.

E-mail address: docnaren@gmail.com (N.P. Rao).

1 Both authors contributed equally to the manuscript.
}

Schizophrenia (SCZ) and Bipolar disorder (BD) (Curtis et al., 1999; Goldstein, 2017; Hudson et al., 1997; Mathew et al., 1988; Rubin et al., 1995; Sun et al., 2009), retinal microvasculature has been examined in SCZ and BD. Increased retinal venular caliber has been found in SCZ (Meier et al., 2013) and twins discordant for psychosis symptoms (Meier et al., 2015). A significant association has also been reported between retinal vascular caliber, diastolic blood pressure, and endothelial function in adolescents with BD, although no differences in vascular caliber were noted between adolescents with BD and healthy volunteers (HV) (Naiberg et al., 2017). Recently, we examined the retinal vascular caliber in SCZ and BD and reported significantly narrower arterioles and wider venules in SCZ and BD compared to HV. In addition, there were also significant differences between SCZ and BD patients; patients with BD had narrower arterioles and wider venules (Appaji et al., 2019). The increased prevalence of comorbid metabolic risk factors is possibly the pathophysiology underlying retinal vascular abnormality. However, the contribution of shared genetic factors cannot be ruled 
out as wider venules have been observed in discordant twins of patients with psychosis symptoms also suggesting that retinal microvasculature may reflect a familial vulnerability to psychosis symptoms (Meier et al., 2015).

Another key parameter measured using fundus imaging is retinal vascular tortuosity or curvature. Tortuosity describes the geometric pattern of the retinal vasculature layout and indicates the adequacy of the state of microcirculation and level of ocular perfusion (Patton et al., 2006). A few studies have reported that retinal vascular tortuosity is a more stable marker as it is not affected by pulse variations (Hao et al., 2012; Kalitzeos et al., 2013) and has high heritability (Kirin et al., 2017; Taarnhøj et al., 2008). Alterations in genetic factors, angiogenesis, blood flow, blood pressure and degeneration of vasculature are implicated in the formation of vessel tortuosity. With vascular disease and aging the internal lamina and tunica media of vessel wall degenerate and gets replaced by fibrous tissue. The resulting mechanical instability may give rise to the development of blood vessel tortuosity (Fredriksson et al., 1988; Han, 2012; Patton et al., 2005; Williams et al., 2015). Mutations in genes responsible for formation of basement membrane proteins, namely LAMA1 and COL4A1, are reported to cause retinal vascular tortuosity (Edwards et al., 2010; Zenteno et al., 2014).

Interestingly, evidence from several lines of research including genetic, neuroimaging and neuropathology suggests a significant role of microvascular anomaly and angiogenesis in the pathogenesis of schizophrenia (Katsel et al., 2017). It is important to note that a few congenital syndromes with retinal vascular tortuosity have high comorbidity of psychoses, SCZ and BD. Previous studies have reported increased retinal vascular tortuosity in 22q11.2 microdeletion syndromes (De Niro et al., 2013). Tortuosity of the retinal vessels, affecting both arterioles and venules, is a common finding and is present in about $30 \%$ of patients with 22q11.2 microdeletion syndrome (Gokturk et al., 2016). It is important to note that 22q11.2 microdeletion syndromes, namely DiGeorge syndrome and Velocardio-facial syndrome (VCFS), are associated with an increased risk of SCZ (Tang et al., 2014). Similarly, retinal vascular tortuosity is reported in Moyamoya disease in which psychoses and mood disorders are common neuropsychiatric comorbidities (Behere et al., 2012; Katsman et al., 2016; Richards et al., 2019). In addition, significant association has been reported between retinal vascular tortuosity and cardiovascular risk factors like carotid intima-medial thickness (CMIT) (Kirin et al., 2017), metabolic syndrome, and diabetes mellitus (Noda et al., 2014). Studies have implicated increased tortuosity of retinal vessels in cerebrovascular diseases like ischemic stroke (Ong et al., 2013), cognitive dysfunction, Alzheimer's dementia (Cheung et al., 2014), and metabolic disorders like high blood pressure, body mass index, and diabetes (Noda et al., 2014).

Considering the possible shared genetic vulnerability and the high prevalence of vascular morbidity in SCZ and BD, we examined retinal vascular tortuosity in SCZ and BD in this study. It is important to note that no study has examined retinal vascular tortuosity in SCZ and BD. We hypothesized that both SCZ and BD would have increased retinal vascular tortuosity compared to healthy volunteers (HV). As SCZ and BD both have increased vascular morbidity (Goldstein, 2017; Hennekens, 2007; Kupfer, 2005; Swartz and Fagiolini, 2012) and shared pathogenic mechanisms (Craddock and Owen, 2010; Meda et al., 2014) we also hypothesized that there would be no difference in retinal vascular tortuosity between $\mathrm{SCZ}$ and BD.

\section{Methodology}

\subsection{Sample}

One hundred patients each with SCZ and BD were recruited from the National Institute of Mental Health and Neurosciences
(NIMHANS), Bengaluru, India, a tertiary care hospital. We recruited patients between 2015 and 2018. Both inpatients and out-patients were recruited. One hundred healthy volunteers (HV) were recruited from the same geographical location through flyers and by word of mouth. All study participants were adults aged between 18 and 50 years. All patients were examined by a board-certified psychiatrist; they met criteria for SCZ or BD as per the International Classification of Disorders 10 (ICD-10). Those patients with concurrent substance abuse or dependence (except nicotine) and comorbid Axis I psychiatric disorders were excluded. All HV were clinically evaluated and administered cross cutting symptom measure checklist by a certified psychiatrist to rule out Axis I psychiatric diagnoses (Clarke and Kuhl, 2014; Narrow et al., 2013). HV were also excluded if they had history of substance use disorder. Participants with serious medical conditions including hypertension, diabetes, stroke, or history of eye trauma and surgery were excluded from the study. The study was approved by the institutional ethics committee and all participants provided written informed consent.

\subsection{Assessments}

After recruitment, the SCZ patients were assessed for severity of clinical symptoms using the Brief Psychiatric Rating Scale (BPRS) (Overall and Gorham, 1962) to measure the severity of positive and negative symptoms and general psychopathology. Young's Mania Rating Scale (YMRS) (Young et al., 1978), and Hamilton Depression Rating Scale (HDRS) (Hamilton, 1960) were used to assess the severity of manic and depressive symptoms respectively in BD. Functioning was assessed using the Global Assessment of Functioning (GAF) (Jones et al., 1995) and Clinical Global Impression (CGI) (Busner and Targum, 2007).

\subsection{Retinal image acquisition}

After the procedure of retinal image acquisition was explained, the participants were seated in a dark room for $5 \mathrm{~min}$ to facilitate auto dilation of the pupil. Images were acquired by a trained individual using a non-mydriatic camera with 40 degrees field of view, 3nethra classic manufactured by Forus Health Pvt. Ltd., Bengaluru, India. Optic disc centred retinal images of both the eyes were acquired using a valid method described elsewhere (Nguyen et al., 2010); the colour fundus image was acquired by illumination of light flashes. A representative image of the acquisition of retinal images is given in Supplementary Fig. S1.

\subsection{Measurement of retinal tortuosity}

An initial quality check was conducted to examine the suitability of images for measurement of tortuosity. Forty-five out of 300 images were excluded following quality check due to inadequate illumination and the remaining 255 images were considered for analysis. These included $78 \mathrm{HV}, 79 \mathrm{SCZ}$, and $86 \mathrm{BD}$. We calculated a measure known as Simple Tortuosity (ST) which is defined as the mean ratio of the arc length (actual traced length of the vessel) to the chord length (length of the straight line drawn from the starting to ending point of the vessel) of vessels in the radial zone between 0.5 to 2disc diameters from the optic disc (Benitez-Aguirre et al., 2011; Benitez-Aguirre et al., 2012) (Supplementary Fig. S2). Arteries and veins were identified and labeled manually. All arteries and veins in the above-said zone were considered for calculation of ST. The arc length and chord length of these vessels were then determined using customized semi-automated software for tortuosity created using MATLAB 2018a (by The MathWorks, Inc., Natick, Massachusetts, United States), similar to other proprietary software (Kalitzeos et al., 2013). ST was calculated for left and right eyes 
separately. Finally, the average of the left and right eye tortuosity indices was calculated. Average retinal venular tortuosity index (RVTI) and average retinal arteriolar tortuosity index (RATI) were calculated separately. A sub-sample of 30 participant images were analyzed by two raters to check inter-rater reliability. A good interrater reliability was obtained between the graders (Intra Class Correlation for RVTI-0.81 and RATI-0.82).

\subsection{Statistical analysis}

All statistical analyses were performed using the Statistical Package for Social Sciences (SPSS) version 25. The data was initially examined for normative distribution using the Shapiro-Wilk test and parametric tests were applied as the data was normatively distributed. The sex distribution across the three groups was examined using the chi-square test and the age difference was analyzed using one-way analysis of variance (ANOVA). As there was a significant difference across groups with respect to age and sex, these were used as covariates in the further analysis. Differences in RVTI and RATI across the three groups were examined using analysis of co-variance (ANCOVA) with age and sex as covariates. As there were two primary outcome measures, a Bonferroni correction of $\alpha=0.05 / 2=0.025$ was considered significant. Post-hoc analysis was conducted to examine differences between pairs of groups. To calculate the extent of contribution by age and sex on RVTI and RATI, we also conducted linear regression analyses with RATI and RVTI as dependent variables and group, age, and sex as predictor variables. To examine the relation between ST and clinical variables, Pearson's correlation analyses were performed with RATI, RVTI and BPRS, YMRS, HDRS, age at onset of illness, duration of illness, and chlorpromazine equivalent of antipsychotic dose (Adams and Nasrallah, 2018). As a subgroup of patients had nicotine dependence, a sub-analysis was conducted after excluding these patients to avoid the confounding effect of nicotine use on retinal vascular tortuosity (Boretsky et al., 2015; Moschos et al., 2016; Yanagi et al., 2014). In addition, a sub-analysis was conducted for sub-group of patients for whom BMI and systolic blood pressure were recorded.

\section{Results}

\subsection{Comparison of demographic variables}

The differences in demographic and clinical variables across the groups are shown in Table 1 . There was a significant difference across the three groups in age and gender distribution. Duration of illness and age at onset of illness were not significantly different in patients with SCZ and BD.

Table 1

Comparison of demographic and clinical details between the groups.

\begin{tabular}{lccccc}
\hline & $\begin{array}{l}\text { HV } \\
(\mathrm{n}=78)\end{array}$ & $\begin{array}{l}\mathrm{SCZ} \\
(\mathrm{n}=79)\end{array}$ & $\begin{array}{l}\mathrm{BD} \\
(\mathrm{n}=86)\end{array}$ & $\mathrm{F} / \mathrm{t} / \chi^{2}$ & $\mathrm{p}$ \\
\hline Age & $30 \pm 7.6$ & $32.7 \pm 6$ & $33.2 \pm 6.2$ & 5.57 & $0.004^{*}$ \\
Gender ratio (M/F) & $35 / 43$ & $55 / 24$ & $50 / 36$ & 9.86 & $0.007^{*}$ \\
Age at onset (years) & - & $25.1 \pm 5.5$ & $23.7 \pm 6$ & 1.7 & 0.19 \\
Duration of illness (years) & - & $7.7 \pm 5.1$ & $8.7 \pm 5.3$ & 1.16 & 0.28 \\
BPRS & - & $28.3 \pm 5.1$ & - & - & - \\
HDRS & - & - & $3.5 \pm 4.7$ & - & - \\
YMRS & - & - & $1.7 \pm 3.0$ & - & - \\
\hline
\end{tabular}

SCZ-patients with schizophrenia; BD-patients with bipolar disorder; HV-healthy volunteer; BPRS-Brief Psychiatric rating scale, HDRS-Hamilton depression rating scale, YMRS-Young's mania rating scale; F-Analysis of Variance; $t$-Independent $t$ test; $\chi 2-$ Chi square test.

* Significant difference.
Table 2

Retinal vascular tortuosity in the three groups.

\begin{tabular}{cccccc}
\hline & HV $(\mathrm{n}=78)$ & $\mathrm{SCZ}(\mathrm{n}=79)$ & $\mathrm{BD}(\mathrm{n}=86)$ & $\mathrm{F}$ & $\mathrm{P}$ \\
\hline RVTI & $1.031 \pm 0.02$ & $1.027 \pm 0.01$ & $1.026 \pm 0.01$ & 2.23 & 0.051 \\
RATI & $1.023 \pm 0.01$ & $1.0312 \pm 0.01$ & $1.038 \pm 0.02$ & 18.87 & $<0.001^{*}$ \\
\hline
\end{tabular}

SCZ-patients with schizophrenia; BD-patients with bipolar disorder; HV-healthy volunteer; F-ANCOVA with age and sex as covariates; RVTI-Average retinal venular tortuosity index; RATI-Average retinal arteriolar tortuosity index.

* Significant difference.

\subsection{Differences in RATI and RVTI between groups}

On ANCOVA, there was a significant difference across the three groups only in RATI $(\mathrm{p}<0.001)$ but not in $\operatorname{RVTI}(\mathrm{p}=0.051)$ (Table 2$)$. On further post-hoc ANOVA both $\mathrm{SCZ}(\mathrm{p}=0.003)$ and $\mathrm{BD}$ $(\mathrm{p}<0.001)$ had significantly higher RATI compared to HV. BD patients also had significantly higher RATI compared to SCZ $(p=0.017)$ (Supplement Table S3). In addition, we calculated the effect size to quantify the magnitude of difference between the groups in RATI. The effect size calculation showed a large effect size between BD and HV $(d=0.91 ; r=0.41)$, a medium effect size between SCZ and HV $(\mathrm{d}=0.73 ; \mathrm{r}=0.33)$; and a small effect size between BD and SCZ ( $d=0.39 ; 0.19)$. To calculate the extent of the contribution of age and sex and to delineate their possible confounding effects on group-wise comparisons, regression analysis was conducted with and without age and sex as additional regressors. The group differences were significant in both instances and the regression coefficients were comparable (Table 3).

In addition, subgroup analyses were done on age and sexmatched sample to rule out confounding effects. $61 \mathrm{HV}$ $(\mathrm{M}: \mathrm{F}=30: 31 ; \quad$ age $=30.4 \pm 6.0$ years $), 68 \mathrm{SCZ} \quad(\mathrm{M}: \mathrm{F}=44: 24$; age $=32.4 \pm 5.3$ years $) \quad$ and $77 \quad \mathrm{BD} \quad(\mathrm{M}: \mathrm{F}=46: 31$; age $=32.53 \pm 5.2$ years) were selected. These three groups were matched on age $(\mathrm{F}=2.89 ; \mathrm{p}=0.06)$ and $\operatorname{sex}\left(\chi^{2}=3.3 ; \mathrm{p}=0.19\right)$. On ANOVA, there was still a significant difference across the three groups on RATI (HV: $1.0232 \pm 0.0099$; SCZ: $1.0312 \pm 0.0128$; BD: $1.0367 \pm 0.0194 ; \mathrm{F}=13.91, \mathrm{p}<0.001)$. As expected, there was no significant difference on RVTI (HV: 1.0302 \pm 0.0136 ; SCZ: $1.0278 \pm 0.0136 ; \mathrm{BD}: 1.0260 \pm 0.0125 ; \mathrm{F}=1.68, \mathrm{p}=0.19$ ).

The results continued to remain significant after excluding the 15 participants who had nicotine dependence (11 SCZ and 4 BD); there was a significant difference between groups on RATI (HV: $1.023 \pm 0.01 ; \quad S C Z$ : $1.031 \pm 0.013 ; \quad B D: 1.038 \pm 0.019 ; \quad F=18.49$; $\mathrm{p}<0.001)$ but no significant difference on RVTI $(\mathrm{HV}=1.03 \pm 0.15$; $\mathrm{SCZ}=1.027 \pm 0.013 ; \mathrm{BD}=1.026 \pm 0.12 ; \mathrm{F}=2.36 ; \mathrm{p}=0.097$ ) (Details in Supplementary Table S1). In a subgroup of patients, BMI [HV $(\mathrm{n}=41)-23.33 \pm 3.4 ; \mathrm{SCZ}(\mathrm{n}=66)-25.14 \pm 5.2 ; \mathrm{BD}(\mathrm{n}=52)-$ $25.93 \pm 4.4]$ and systolic blood pressure [HV $(n=23)-115.87 \pm 8.0$; SCZ $(n=49)-118.12 \pm 11.6$; BD $(n=72)-117.4 \pm 10.6]$ were recorded on the day of the retinal vascular examination. Even after controlling for these variables in the regression analysis, there was no significant difference in the findings and results remained significant for RATI (Table 4). On Pearson's correlation analysis, there was no significant correlation between the RATI and clinical variables BPRS, YMRS, HDRS, age at onset of illness and duration of illness ( $p>0.05)$ (Supplementary Table S2).

\section{Discussion}

To the best of our knowledge, this is the first study to examine retinal vascular tortuosity in patients with SCZ and BD in comparison to HV. Results of the study suggest significantly increased RATI in both BD and SCZ compared to HV. However, there was no significant difference across the groups with respect to RVTI. Studies which examined retinal vascular caliber in SCZ and BD have 
Table 3

Mean difference of retinal tortuosity between groups adjusted for age and sex.

\begin{tabular}{|c|c|c|c|c|c|c|}
\hline \multirow[t]{2}{*}{ Variable } & \multirow[t]{2}{*}{ Group } & & \multicolumn{2}{|l|}{ Not adjusted for age and sex } & \multicolumn{2}{|l|}{ Adjusted for age and sex } \\
\hline & & & $\beta(95 \% \mathrm{CI})$ & $\mathrm{p}$ & $\beta(95 \% \mathrm{CI})$ & $\mathrm{p}$ \\
\hline \multirow[t]{3}{*}{ RVTI } & HV & SCZ & $-0.003(-0.008$ to 0.001$)$ & 0.124 & $0.004(-0.009$ to 0.000$)$ & 0.054 \\
\hline & HV & $\mathrm{BD}$ & $-0.004(-0.008$ to 0.000$)$ & $0.044^{*}$ & $-0.005(-0.009$ to -0.001$)$ & $0.021^{*}$ \\
\hline & SCZ & $\mathrm{BD}$ & $-0.001(-0.005$ to 0.003$)$ & 0.65 & $-0.001(-0.005$ to 0.003$)$ & 0.741 \\
\hline \multirow[t]{3}{*}{ RATI } & HV & SCZ & $0.008(0.004$ to 0.011$)$ & $0.001^{*}$ & 0.007 (0.002 to 0.012$)$ & $<0.005^{*}$ \\
\hline & HV & $\mathrm{BD}$ & $0.014(0.019$ to 0.009$)$ & $<0.001^{*}$ & $0.014(0.009$ to 0.018$)$ & $<0.001^{*}$ \\
\hline & SCZ & $\mathrm{BD}$ & $0.006(0.002$ to 0.011$)$ & $0.006^{*}$ & $0.007(0.002$ to 0.011$)$ & $0.005^{*}$ \\
\hline
\end{tabular}

SCZ-patients with schizophrenia; BD-patients with bipolar disorder; HV-healthy volunteer; $\beta$-regression coefficient, 95\% CI-95\% confidence interval.

Significant difference.

reported abnormalities in the vascular caliber (Appaji et al., 2019; Meier et al., 2013, 2015, 2016). Our findings of increased retinal arteriolar tortuosity provide added evidence for retinal vascular abnormalities in SCZ and BD.

A few studies have reported associations between neuropsychiatric conditions and retinal vascular tortuosity; increased RATI has been reported to be associated with ischemic stroke (Ong et al., 2013) and Alzheimer's disease (Cheung et al., 2014). Although retinal vascular tortuosity has not been examined earlier in SCZ or $\mathrm{BD}$, a previous case report has reported increased retinal vascular tortuosity in a patient with SCZ and DiGeorge syndrome (De Niro et al., 2013). Interestingly, previous studies have also reported increased retinal vascular tortuosity in a considerable proportion of individuals with 22q11.2 deletion and duplication syndromes (Casteels et al., 2008; Cordovez et al., 2014; Hill et al., 2004). These syndromes have a significantly increased prevalence of SCZ (Van et al., 2017). Our finding of increased tortuosity in retinal arterioles of BD and SCZ provides further support to its association with neuropsychiatric syndromes.

Several studies have suggested that retinal vascular measures are reliable surrogate markers for increased risk of adverse vascular events (Kalitzeos et al., 2013; Witt et al., 2006). It is important to note that patients with SCZ and BD have significantly increased rates of adverse cardio/cerebrovascular events (Lin et al., 2008; Newcomer, 2006; Penninx and Lange, 2018; Prieto et al., 2014) and this increased rate exceeds what can be explained by traditional cardiovascular risk factors and life style (Goldstein et al., 2015). Examination of retinal microvascular tortuosity could prove to be an easy and affordable method to identify these patients. Although our study is cross-sectional in design, it provides a rationale for further examination of retinal vascular tortuosity using longitudinal study designs. This could examine whether increased retinal arteriolar tortuosity confers greater risk of adverse vascular events in SCZ and BD. If predictive utility can be demonstrated, retinal examination for arteriolar tortuosity could help in screening individuals with SCZ and BD at risk for developing adverse vascular events.

The pathophysiology behind retinal venular and arteriolar abnormalities is still unclear. Several genetic and environmental

Table 4

Details of regression coefficient between groups with BMI and Systolic blood pressure as covariates.

\begin{tabular}{|c|c|c|c|c|c|}
\hline \multirow{2}{*}{$\begin{array}{l}\text { Retinal arterial } \\
\text { tortuosity } \\
\text { index (RATI) }\end{array}$} & \multicolumn{2}{|c|}{$\begin{array}{l}\text { Unstandardized } \\
\text { coefficients }\end{array}$} & \multirow{2}{*}{$\begin{array}{l}\text { Standardized } \\
\text { coefficients } \\
\text { Beta }\end{array}$} & \multirow[t]{2}{*}{$\mathrm{t}$} & \multirow[t]{2}{*}{ Sig. } \\
\hline & B & Std. Error & & & \\
\hline (Constant) & 0.988 & 0.029 & & 34.67 & $<0.001^{*}$ \\
\hline Group & 0.014 & 0.005 & 0.304 & 2.546 & $0.013^{*}$ \\
\hline Body mass index & 0.000 & 0.001 & 0.042 & 0.343 & 0.733 \\
\hline $\begin{array}{l}\text { Systolic Blood } \\
\text { pressure }\end{array}$ & 0.000 & 0.000 & 0.094 & 0.761 & 0.450 \\
\hline
\end{tabular}

* Significant difference. theories have been proposed. Vascular tortuosity has been shown to have a high degree of heritability (Kirin et al., 2017; Taarnhøj et al., 2008). While retinal vascular caliber has strong associations with cardiovascular biochemical markers and hypertension, retinal vascular tortuosity is less influenced by these measures (Kirin et al., 2017; Taarnhøj et al., 2008). On the other hand, Carotid intimamedial thickness (CMIT) has significant associations with retinal vascular tortuosity (Kirin et al., 2017). Considering the direct relation of CIMT with stroke and myocardial infarction (Lorenz et al., 2007), the association between retinal vascular tortuosity and CIMT supports the use of retinal vascular tortuosity as a non-invasive surrogate marker for stratifying the risk of future adverse cardio/ cerebrovascular events (Kalitzeos et al., 2013). In addition to these genetic factors, several inflammatory factors associated with metabolic syndrome and diabetes mellitus are also associated with increased retinal vascular tortuosity (Noda et al., 2014). Whether similar mechanisms operate in patients with SCZ and BD is yet to be examined. At this stage, we are unclear whether increased retinal arteriolar tortuosity seen in our study may be reflective of the risk of higher prevalence of metabolic syndrome and cardio/cerebrovascular adverse events in SCZ and BD (Newcomer, 2006; Penninx and Lange, 2018). However, other mechanisms also need to be considered as studies in children with 22q11.2 deletion syndrome have reported increased retinal vascular tortuosity even in the absence of vascular adverse events (Casteels et al., 2008). Familial retinal arteriolar tortuosity, a disorder with autosomal dominant inheritance is caused by mutations in gene COL4A1, which codes for a major basement membrane (Sutter and Helbig, 2003; Zenteno et al., 2014). Interestingly, mutations in COL4A1 gene are also known to cause cerebral cortical malformations and neuronal localization defects (Labelle-Dumais et al., 2011). Interestingly, the same gene is implicated in altered synaptic elements in superior temporal cortex of schizophrenia patients (Schmitt et al., 2012). Hence, at this stage it is not possible to confidently infer whether the increased retinal arteriolar tortuosity in SCZ and BD is the consequence of comorbid cardiovascular risk factors or manifestation of shared genetic vulnerability. Future studies need to incorporate genetic testing in addition to examination of retinal vascular tortuosity for further clarity.

The significant difference in RATI between SCZ and BD was not expected and did not conform to our hypothesis. Considering the shared pathogenic factors (Craddock and Owen, 2010) and increased prevalence of vascular adverse events (Newcomer, 2006) in both SCZ and BD, we did not expect any difference between SCZ and $\mathrm{BD}$. Only a few studies have reported differences in cognitive functions, brain structure/function, comorbidities between SCZ and BD (Bora, 2016; Grover et al., 2014; Rao et al., 2010; Redpath et al., 2013; Whalley et al., 2012); most other studies have reported significant overlap between SCZ and BD in genetics, brain structure and function (Craddock and Owen, 2010; Pearlson, 2015). We do not have a definitive explanation for this difference at this stage. At this stage our finding of difference between SCZ and BD must be 
considered preliminary, requiring further examination in future studies. Similarly, we do not have definitive explanations for the absence of difference between groups in RVTI measurements. A few studies have suggested differential association between retinal arteriolar and venular tortuosity and cardiovascular risk factors and diabetes (Cheung et al., 2011b; Sasongko et al., 2016). Though tortuosity can be measured in both retinal arteries and veins, but arteriolar tortuosity is examined more frequently than venular tortuosity. Arteriolar tortuosity changes have been related to arteriosclerosis (Stokoe and Turner, 1966) and venular tortuosity have been connected to vascular obstruction/occlusion (Varner, 2019). Anatomically, presence of tunica media makes arteriolar wall thicker and less compliant than venular wall (Koh et al., 2010). Whether the difference between arterioles and venules seen in our study is due to mechanical reasons only or not need to be examined in the future.

The following limitations need to be considered while interpreting the results of the study. All patients were on pharmacological treatment and the effects of medication on retinal arteriolar tortuosity are not known. Although there was no correlation between the dosage of antipsychotic and retinal arteriolar tortuosity, the confounding effects of medications cannot be definitively ruled out with the current study design. Examining drug-naïve patients' needs to be considered in future studies. We did not record blood pressure and glucose levels on the day of the assessment. As the participants were young, those with hypertension or diabetes were excluded based on history; one cannot rule out the confounding effect of Pre-diabetic or pre-hypertensive status which may be missed in history (Benitez-Aguirre et al., 2011; Nguyen et al., 2007). The relation between retinal vascular tortuosity and hypertension is still debated; while no association was reported between blood pressure and retinal vascular tortuosity in one study (Kirin et al., 2017), significant association has been reported in other studies (Cheung et al., 2011a,b). Future studies need to consider recording blood pressure, fasting blood glucose, renal functions, and life style factors like diet and exercise at the time of retinal vascular assessment. We did not collect the information of family history of cardio/cerebrovascular disorders in study participants which could affect the findings. Future studies need to consider collecting the family history of cardiovascular disorders. Although individual group differences could be detected using the current sample size, larger studies are required for sub-group analysis (ex: BD-I vs BD-II vs SCZ; BD with psychotic symptoms vs BD without psychotic symptoms VS SCZ etc.). Finally, we used the Fagerstrom test for nicotine dependence (FTND) scores as covariate in the analysis. While this could control for the nicotine dependence, this will not control for the confounding effect of the non-dependence pattern of nicotine use which may influence retinal vessel tortuosity as it is shown to be related to venular diameter (Hughes et al., 2009). Future studies could use smoking status as a covariate instead of or in addition to FTND.

We recruited participants with no current comorbid psychiatric conditions as the effect of comorbid conditions on retinal vascular tortuosity is not known. While this resulted in a homogeneous sample with SCZ and BD, this could affect generalizability of findings. Similarly, as the retinal image acquisition required participant to sit still in a dark room for 5 min, a major portion of the participants were in euthymic phase. This could have resulted the absence of relation between retinal vascular tortuosity and clinical symptoms. Future studies need to consider inclusion of participants in different stages of illness and comorbidities so that the relation between retinal vascular parameters and acute symptoms, course of the illness in preceding years and sleep disturbances could be examined. Such analyses could potentially reveal the factors underlying the difference between $\mathrm{BD}$ and $\mathrm{SCZ}$ seen in the current study. Considering that the retinal vascular caliber and tortuosity measure different aspects of vascular abnormality and provide complementary information, future studies could consider simultaneous measurement of different retinal vascular parameters to arrive at a composite index in SCZ and BD.

\section{Conclusion}

Our study indicates significantly increased retinal arteriolar tortuosity in patients with BD and SCZ when compared to HV, and possible differences between $\mathrm{SCZ}$ and BD. These preliminary findings provide a strong rationale for further systematic examination of retinal arteriolar tortuosity in patients with $\mathrm{SCZ}$ and $\mathrm{BD}$. Considering the easy accessibility, non-invasive nature of the examination, and affordability, retinal arteriolar tortuosity examination can be conducted even in outpatient psychiatry settings and could serve as a surrogate marker for abnormalities in the cerebral vasculature. If shown to be of predictive utility in future longitudinal studies, examination of retinal arteriolar tortuosity has the potential to identify BD and SCZ patients at risk of developing adverse vascular events.

\section{Contributors}

AA, NPR, TJB were involved in the conceptualization design of the study, analysis of data, interpretation of results and manuscript preparation. AA, BN, AP, AJ, CH, DMC were involved in data collection and data analysis. SV, MK, GV, SVR, CW were involved in the interpretation of results and manuscript preparation. AA, BN and NPR wrote the first draft of the manuscript and all authors contributed to revisions. All authors have approved the final manuscript.

\section{Funding source}

Dr. Naren P. Rao is supported by the Department of Biotechnology, Ministry of Science and Technology, India-IYBA/2015/09. The funding agency did not have role in design of study or interpretation of results.

\section{Declaration of competing interest}

Dr. Shyam Vasudeva Rao is Co-founder and Director at Forus Health Pvt. Ltd., India. Other authors report no conflict of interest.

\section{Acknowledgments}

None.

\section{Appendix A. Supplementary data}

Supplementary data to this article can be found online at https://doi.org/10.1016/j.schres.2019.08.020.

\section{References}

Adams, S.A., Nasrallah, H.A., 2018. Multiple retinal anomalies in schizophrenia. Schizophr. Res. 195, 3-12.

Appaji, A., Nagendra, B., Chako, D.M., Padmanabha, A., Hiremath, C.V., Jacob, A., Varambally, S., Keshavan, M., Venkatasubramanian, G., Rao, S.V., Webers, C.A.B. Berendschot, T.T.J.M., Rao, N.P., 2019. Retinal vascular abnormalities in schizophrenia and bipolar disorder: a window to the brain. Bipolar Disorder. https:// doi.org/10.1111/bdi.12779 (Epub ahead of print)

Behere, R.V, John, M. Sureshkumar, R., Varambally, S. Rao, N.P. Venkatasubramanian, G., Gangadhar, B., 2012. Mood disorder in association with moyamoya disease. Psychiatry Clin. Neurosci. 66 (2), 163-164.

Benitez-Aguirre, P., Craig, M.E., Sasongko, M.B., Jenkins, A.J., Wong, T.Y., Wang, J.J., Cheung, N., Donaghue, K.C., 2011. Retinal vascular geometry predicts incident retinopathy in young people with type 1 diabetes: a prospective cohort study from adolescence. Diabetes Care 34 (7), 1622-1627. 
Benitez-Aguirre, P.Z., Sasongko, M.B., Craig, M.E., Jenkins, A.J., Cusumano, J., Cheung, N., Wong, T.Y., Donaghue, K.C., 2012. Retinal vascular geometry predicts incident renal dysfunction in young people with type 1 diabetes. Diabetes Care 35 (3), 599-604.

Bora, E., 2016. Differences in cognitive impairment between schizophrenia an bipolar disorder: considering the role of heterogeneity. Psychiatry Clin. Neurosci. 70 (10), 424-433.

Boretsky, A., Gupta, P., Tirgan, N., Liu, R., Godley, B.F., Zhang, W., Tilton, R.G., Motamedi, M., 2015. Nicotine accelerates diabetes-induced retinal changes. Curr. Eye Res. 40 (4), 368-377.

Busner, J., Targum, S.D., 2007. The clinical global impressions scale: applying a research tool in clinical practice. Psychiatry (Edgmont) 4 (7), 28-37.

Casteels, I., Casaer, P., Gewillig, M., Swillen, A., Devriendt, K., 2008. Ocular findings in children with a microdeletion in chromosome 22q11.2. Eur. J. Pediatr. 167 (7), $751-755$.

Cheung, N., Mosley, T., Islam, A., Kawasaki, R., Sharrett, A.R., Klein, R., Coker, L.H., Knopman, D.S., Shibata, D.K., Catellier, D., Wong, T.Y., 2010 Retinal microvascular abnormalities and subclinical magnetic resonance imaging brain infarct: a prospective study. Brain: A Journal of Neurology 133, 1987-1993. Pt 7.

Cheung, C.Y., Tay, W.T., Mitchell, P., Wang, J.J., Hsu, W., Lee, M.L., Lau, Q.P., Zhu, A.L. Klein, R., Saw, S.M., Wong, T.Y., 2011. Quantitative and qualitative retina microvascular characteristics and blood pressure. J. Hypertens. 29 (7), 1380-1391.

Cheung, C.Y., Zheng, Y., Hsu, W., Lee, M.L., Lau, Q.P., Mitchell, P., Wang, J.J., Klein, R., Wong, T.Y., 2011. Retinal vascular tortuosity, blood pressure, and cardiovascular risk factors. Ophthalmology 118 (5), 812-818.

Cheung, C.Y., Ong, Y.T., Ikram, M.K., Ong, S.Y., Li, X., Hilal, S., Catindig, J.A. Venketasubramanian, N., Yap, P., Seow, D., Chen, C.P., Wong, T.Y., 2014. Microvascular network alterations in the retina of patients with Alzheimer's disease. Alzheimers Dement. 10 (2), 135-142.

Clarke, D.E., Kuhl, E.A., 2014. DSM-5 cross-cutting symptom measures: a step towards the future of psychiatric care? World Psychiatry: Official Journal of the World Psychiatric Association (WPA) 13 (3), 314-316.

Cordovez, J.A., Capasso, J., Lingao, M.D., Sadagopan, K.A., Spaeth, G.L., Wasserman, B.N., Levin, A.V., 2014. Ocular manifestations of 22q11. 2 microduplication. Ophthalmology 121 (1), 392-398.

Craddock, N., Owen, M.J., 2010. The Kraepelinian dichotomy - going, going... But still not gone. Br. J. Psychiatry 196 (2), 92-95.

Curtis, C.E., Iacono, W.G., Beiser, M., 1999. Relationship between nailfold plexus visibility and clinical, neuropsychological, and brain structural measures in schizophrenia. Biol. Psychiatry 46 (1), 102-109.

de Jong, F.J., Schrijvers, E.M., Ikram, M.K., Koudstaal, P.J., de Jong, P.T., Hofman, A., Vingerling, J.R., Breteler, M.M., 2011. Retinal vascular caliber and risk of dementia: the Rotterdam study. Neurology 76 (9), 816-821.

De Niro, J.E., Randhawa, S., McDonald, H.R., 2013. Retinal vascular tortuosity in DiGeorge syndrome complicated by solar retinopathy. Retinal Cases and Brief Reports 7 (4), 343-346.

Edwards, M.M., Mammadova-Bach, E., Alpy, F., Klein, A., Hicks, W.L., Roux, M., Simon-Assmann, P., Smith, R.S., Orend, G., Wu, J., Peachey, N.S., Naggert, J.K. Lefebvre, O., Nishina, P.M., 2010. Mutations in Lama1 disrupt retinal vascular development and inner limiting membrane formation. J. Biol. Chem. 285 (10), 7697-7711.

Fredriksson, K., Nordborg, C., Kalimo, H., Olsson, Y., Johansson, B., 1988. Cerebra microangiopathy in stroke-prone spontaneously hypertensive rats. Acta Neuropathol. 75 (3), 241-252.

Gokturk, B., Topcu-Yilmaz, P., Bozkurt, B., Yildirim, M.S., Guner, S.N., Sayar, E.H. Reisli, I., 2016. Ocular findings in children with 22q11.2 deletion syndrome. J. Pediatr. Ophthalmol. Strabismus 53 (4), 218-222.

Goldstein, B.I., 2017. Bipolar disorder and the vascular system: mechanisms and new prevention opportunities. Can J Cardiol 33 (12), 1565-1576.

Goldstein, B.I., Carnethon, M.R., Matthews, K.A., McIntyre, R.S., Miller, G.E., Raghuveer, G., Stoney, C.M., Wasiak, H., McCrindle, B.W., American Heart Association, A., Hypertension, Obesity in Youth Committee of the Council on Cardiovascular Disease in the, Y, 2015. Major depressive disorder and bipolar disorder predispose youth to accelerated atherosclerosis and early cardiovascular disease: a scientific statement from the American Heart Association. Circulation 132 (10), 965-986.

Grover, S., Nebhinani, N., Chakrabarti, S., Avasthi, A., Kulhara, P., Basu, D., Mattoo, S.K., Malhotra, S., 2014. Comparative study of prevalence of metabolic syndrome in bipolar disorder and schizophrenia from North India. Nord Psychiatry 68 (1), 72-77.

Hamilton, M., 1960. A rating scale for depression. J. Neurol. Neurosurg. Psychiatry 23, 56-62.

Han, H.-C., 2012. Twisted blood vessels: symptoms, etiology and biomechanical mechanisms. J. Vasc. Res. 49 (3), 185-197.

Hao, H., Sasongko, M.B., Wong, T.Y., Che Azemin, M.Z., Aliahmad, B., Hodgson, L., Kawasaki, R., Cheung, C.Y., Wang, J.J., Kumar, D.K., 2012. Does retinal vascula geometry vary with cardiac cycle? Invest. Ophthalmol. Vis. Sci. 53 (9), 5799-5805.

Hennekens, C.H., 2007. Increasing global burden of cardiovascular disease in general populations and patients with schizophrenia. J Clin Psychiatry 68 (Suppl. 4), 4-7.

Hill, V.E., Pietucha, S., Ells, A.L., 2004. Congenital vascular tortuosity in DiGeorge syndrome mimicking significant retinopathy of prematurity. Arch. Ophthalmol. $122(1), 132-133$.
Hudson, C.J., Lin, A., Cogan, S., Cashman, F., Warsh, J.J., 1997. The niacin challenge test: clinical manifestation of altered transmembrane signal transduction in schizophrenia? Biol. Psychiatry 41 (5), 507-513.

Hughes, A.D., Wong, T.Y., Witt, N., Evans, R., Thom, S.A., Klein, B.E., Chaturvedi, N., Klein, R., 2009. Determinants of retinal microvascular architecture in normal subjects. Microcirculation 16 (2), 159-166.

Jones, S.H., Thornicroft, G., Coffey, M., Dunn, G., 1995. A brief mental health outcome scale-reliability and validity of the Global Assessment of Functioning (GAF). Br. J. Psychiatry 166 (5), 654-659.

Kalitzeos, A.A., Lip, G.Y., Heitmar, R., 2013. Retinal vessel tortuosity measures and their applications. Exp. Eye Res. 106, 40-46.

Katsel, P., Roussos, P., Pletnikov, M., Haroutunian, V., 2017. Microvascular anomaly conditions in psychiatric disease. Schizophrenia - angiogenesis connection. Neurosci. Biobehav. Rev. 77, 327-339.

Katsman, D., Klufas, M.A., Sarraf, D., Sadda, S., 2016. Retinal arterial tortuosity in Moyamoya disease. JAMA Ophthalmol 134 (1), 111-114.

Kim, D.H., Newman, A.B., Hajjar, I., Strotmeyer, E.S., Klein, R., Newton, E., Sarnak, M.J., Burke, G.L., Lipsitz, L.A., 2011. Retinal microvascular signs and functional loss in older persons: the cardiovascular health study. Stroke 42 (6), 1589-1595.

Kirin, M., Nagy, R., MacGillivray, T.J., Polašek, O., Hayward, C., Rudan, I., Campbell, H., Wild, S., Wright, A.F., Wilson, J.F., 2017. Determinants of retinal microvascular features and their relationships in two European populations. J. Hypertens. 35 (8), 1646.

Koh, V., Cheung, C.Y., Zheng, Y., Wong, T.Y., Wong, W., Aung, T., 2010. Relationship of retinal vascular tortuosity with the neuroretinal rim: the Singapore Malay Eye Study. Invest. Ophthalmol. Vis. Sci. 51 (7), 3736-3741.

Kupfer, D.J., 2005. The increasing medical burden in bipolar disorder. Jama 293 (20), 2528-2530.

Labelle-Dumais, C., Dilworth, D.J., Harrington, E.P., de Leau, M., Lyons, D., Kabaeva, Z., Manzini, M.C., Dobyns, W.B., Walsh, C.A., Michele, D.E., Gould, D.B., 2011. COL4A1 mutations cause ocular dysgenesis, neuronal localization defects, and myopathy in mice and Walker-Warburg syndrome in humans. PLoS Genet. 7 (5), e1002062.

Lesage, S.R., Mosley, T.H., Wong, T.Y., Szklo, M., Knopman, D., Catellier, D.J., Cole, S.R., Klein, R., Coresh, J., Coker, L.H., Sharrett, A.R., 2009. Retinal microvascular abnormalities and cognitive decline: the ARIC 14-year follow-up study. Neurology 73 (11), 862-868.

Lin, H.C., Hsiao, F.H., Pfeiffer, S., Hwang, Y.T., Lee, H.C., 2008. An increased risk of stroke among young schizophrenia patients. Schizophr. Res. 101 (1-3), 234-241.

Lorenz, M.W., Markus, H.S., Bots, M.L., Rosvall, M., Sitzer, M., 2007. Prediction of clinical cardiovascular events with carotid intima-media thickness: a systematic review and meta-analysis. Circulation 115 (4), 459-467.

Mathew, R.J., Wilson, W.H., Tant, S.R., Robinson, L., Prakash, R., 1988. Abnormal resting regional cerebral blood flow patterns and their correlates in schizophrenia. Arch. Gen. Psychiatry 45 (6), 542-549.

Meda, S.A., Ruano, G., Windemuth, A., O'Neil, K., Berwise, C., Dunn, S.M., Boccaccio, L.E., Narayanan, B., Kocherla, M., Sprooten, E., Keshavan, M.S., Tamminga, C.A., Sweeney, J.A., Clementz, B.A., Calhoun, V.D., Pearlson, G.D., 2014. Multivariate analysis reveals genetic associations of the resting default mode network in psychotic bipolar disorder and schizophrenia. Proc. Natl. Acad. Sci. U. S. A. 111 (19), E2066-E2075.

Meier, M.H., Shalev, W., Moffitt, T.E., Kapur, S., Keefe, R.S.E., Wong, T.Y., Belsky, D.W., Harrington, H.L., Hogan, S., Houts, R., Caspi, A., Poulton, R., 2013. Microvascular abnormality in schizophrenia as shown by retinal imaging. Am. J. Psychiatr. 170 (12), 1451-1459.

Meier, M.H., Gillespie, N.A., Hansell, N.K., Hewitt, A.W., Hickie, I.B., Lu, Y., McGrath, J. MacGregor, S., Medland, S.E., Sun, C., Wong, T.Y., Wright, M.J., Zhu, G., Martin, N.G., Mackey, D.A., 2015. Retinal microvessels reflect familial vulnerability to psychotic symptoms: a comparison of twins discordant for psychotic symptoms and controls. Schizophr. Res. 164 (1-3), 47-52.

Meier, M.H., Hill, M.L., Breitborde, N.J.K., 2016. Retinal imaging: a new tool for studying underlying liability to cardiovascular disease in schizophrenia. Curr. Psychiatr. Rev. 12 (4), 326-334.

Moschos, M.M., Nitoda, E., Laios, K., Ladas, D.S., Chatziralli, I.P., 2016. The impact of chronic tobacco smoking on retinal and choroidal thickness in Greek population. Oxidative Med. Cell. Longev. 2016, 2905789.

Naiberg, M.R., Hatch, J.K., Selkirk, B., Fiksenbaum, L., Yang, V., Black, S., Kertes, P.J., Goldstein, B.I., 2017. Retinal photography: a window into the cardiovascularbrain link in adolescent bipolar disorder. J. Affect. Disord. 218, 227-237.

Narrow, W.E., Clarke, D.E., Kuramoto, S.J., Kraemer, H.C., Kupfer, D.J., Greiner, L., Regier, D.A., 2013. DSM-5 field trials in the United States and Canada, part III: development and reliability testing of a cross-cutting symptom assessment for DSM-5. Am. J. Psychiatry 170 (1), 71-82.

Newcomer, J.W., 2006. Medical risk in patients with bipolar disorder and schizophrenia. The Journal of Clinical Psychiatry 67, 25-30 (discussion 36-42).

Nguyen, T.T., Wang, J.J., Wong, T.Y., 2007. Retinal vascular changes in pre-diabetes and prehypertension: new findings and their research and clinical implications. Diabetes Care 30 (10), 2708-2715.

Nguyen, T.T., Islam, F.M., Farouque, H.M., Klein, R., Klein, B.E., Cotch, M.F., Herrington, D.M., Wong, T.Y., 2010. Retinal vascular caliber and brachial flowmediated dilation: the Multi-Ethnic Study of Atherosclerosis. Stroke 41 (7), 1343-1348

Noda, K., Nakao, S., Zandi, S., Sun, D., Hayes, K.C., Hafezi-Moghadam, A., 2014 Retinopathy in a novel model of metabolic syndrome and type 2 diabetes: new 
insight on the inflammatory paradigm. FASEB J. 28 (5), 2038-2046.

Ong, Y.T., De Silva, D.A., Cheung, C.Y., Chang, H.M., Chen, C.P., Wong, M.C., Wong, T.Y., Ikram, M.K., 2013. Microvascular structure and network in the retina of patients with ischemic stroke. Stroke 44 (8), 2121-2127.

Overall, J.E., Gorham, D.R., 1962. The brief psychiatric rating scale. Psychol. Rep. 10 (3), 799-812.

Patton, N., Aslam, T., Macgillivray, T., Pattie, A., Deary, I.J., Dhillon, B., 2005. Retinal vascular image analysis as a potential screening tool for cerebrovascular disease: a rationale based on homology between cerebral and retinal microvasculatures. J. Anat. 206 (4), 319-348.

Patton, N., Aslam, T.M., MacGillivray, T., Deary, I.J., Dhillon, B., Eikelboom, R.H., Yogesan, K., Constable, I.J., 2006. Retinal image analysis: concepts, applications and potential. Prog. Retin. Eye Res. 25 (1), 99-127.

Pearlson, G.D., 2015. Etiologic, phenomenologic, and endophenotypic overlap of schizophrenia and bipolar disorder. Annu. Rev. Clin. Psychol. 11, 251-281.

Penninx, B.W., Lange, S.M., 2018. Metabolic syndrome in psychiatric patients: overview, mechanisms, and implications. Dialogues Clin. Neurosci. 20 (1), 63.

Prieto, M.L., Cuellar-Barboza, A.B., Bobo, W.V., Roger, V.L., Bellivier, F., Leboyer, M., West, C.P., Frye, M.A., 2014. Risk of myocardial infarction and stroke in bipolar disorder: a systematic review and exploratory meta-analysis. Acta Psychiatr. Scand. 130 (5), 342-353.

Rao, N.P., Arasappa, R., Reddy, N.N., Venkatasubramanian, G., Gangadhar, B.N., 2010. Antithetical asymmetry in schizophrenia and bipolar affective disorder: a line bisection study. Bipolar Disord. 12 (3), 221-229.

Redpath, H.L., Cooper, D., Lawrie, S.M., 2013. Imaging symptoms and syndromes: similarities and differences between schizophrenia and bipolar disorder. Biol. Psychiatry 73 (6), 495-496.

Richards, M., Grzenda, A., Nelson, E., Gitlin, M., 2019. Psychiatric comorbidity in Moyamoya disease and preliminary guidelines for treatment. Am. J. Psychiatry 176 (4), 269-274.

Rubin, E., Sackeim, H.A., Prohovnik, I., Moeller, J.R., Schnur, D.B., Mukherjee, S., 1995. Regional cerebral blood flow in mood disorders: IV. Comparison of mania and depression. Psychiatry Res. 61 (1), 1-10.

Sasongko, M.B., Wong, T.Y., Nguyen, T.T., Cheung, C.Y., Shaw, J.E., Kawasaki, R., Lamoureux, E.L., Wang, J.J., 2016. Retinal vessel tortuosity and its relation to traditional and novel vascular risk markers in persons with diabetes. Curr. Eye Res. 41 (4), 551-557.

Schmitt, A., Leonardi-Essmann, F., Durrenberger, P.F., Wichert, S.P., Spanagel, R., Arzberger, T., Kretzschmar, H., Zink, M., Herrera-Marschitz, M., Reynolds, R., Rossner, M.J., Falkai, P., Gebicke-Haerter, P.J., 2012. Structural synaptic elements are differentially regulated in superior temporal cortex of schizophrenia patients. Eur. Arch. Psychiatry Clin. Neurosci. 262 (7), 565-577.

Stokoe, N., Turner, R., 1966. Normal retinal vascular pattern. Arteriovenous ratio as a measure of arterial calibre. Br. J. Ophthalmol. 50 (1), 21.

Sun, C., Wang, J.J., Mackey, D.A., Wong, T.Y., 2009. Retinal vascular caliber: systemic, environmental, and genetic associations. Surv. Ophthalmol. 54 (1), 74-95.
Sutter, F.K., Helbig, H., 2003. Familial retinal arteriolar tortuosity: a review. Surv. Ophthalmol. 48 (3), 245-255.

Swartz, H.A., Fagiolini, A., 2012. Cardiovascular disease and bipolar disorder: risk and clinical implications. J Clin Psychiatry 73 (12), 1563-1565.

Taarnhøj, N., Munch, I., Sander, B., Kessel, L., Hougaard, J., Kyvik, K., Sørensen, T.L. Larsen, M., 2008. Straight versus tortuous retinal arteries in relation to blood pressure and genetics. Br. J. Ophthalmol. 92 (8), 1055-1060.

Tang, S.X., Yi, J.J., Calkins, M.E., Whinna, D.A., Kohler, C.G., Souders, M.C., McDonaldMcGinn, D.M., Zackai, E.H., Emanuel, B.S., Gur, R.C., Gur, R.E., 2014. Psychiatric disorders in 22q11.2 deletion syndrome are prevalent but undertreated. Psychol. Med. 44 (6), 1267-1277.

Van, L., Boot, E., Bassett, A.S., 2017. Update on the 22q11. 2 deletion syndrome and its relevance to schizophrenia. Current Opinion in Psychiatry 30 (3), 191-196.

Varner, P., 2019. Significance of asymmetric retinal vasculature tortuosity - report of 10 consecutive cases. Acta Scientific Ophthalmology 2, 5.

Whalley, H.C., Papmeyer, M., Sprooten, E., Lawrie, S.M., Sussmann, J.E. McIntosh, A.M., 2012. Review of functional magnetic resonance imaging studies comparing bipolar disorder and schizophrenia. Bipolar Disord. 14 (4), 411-431.

Williams, M.A., McGowan, A.J., Cardwell, C.R., Cheung C.Y., Craig, D., Passmore, P. Silvestri, G., Maxwell, A.P., McKay, G.J., 2015. Retinal microvascular network attenuation in Alzheimer's disease. Alzheimer's \& Dementia (Amsterdam, Netherlands) 1 (2), 229-235.

Witt, N., Wong, T.Y., Hughes, A.D., Chaturvedi, N., Klein, B.E., Evans, R McNamara, M., Thom, S.A., Klein, R., 2006. Abnormalities of retinal microvascular structure and risk of mortality from ischemic heart disease and stroke. Hypertension 47 (5), 975-981.

Wong, T.Y., Klein, R., Klein, B.E., Tielsch, J.M., Hubbard, L., Nieto, F.J., 2001. Retinal microvascular abnormalities and their relationship with hypertension, cardiovascular disease, and mortality. Surv. Ophthalmol. 46 (1), 59-80.

Wong, T.Y., Klein, R., Sharrett, A.R., Nieto, F.J., Boland, L.L., Couper, D.J., Mosley, T.H., Klein, B.E., Hubbard, L.D., Szklo, M., 2002. Retinal microvascular abnormalities and cognitive impairment in middle-aged persons: the Atherosclerosis Risk in Communities Study. Stroke 33 (6), 1487-1492.

Yanagi, M., Misumi, M., Kawasaki, R., Takahashi, I., Itakura, K., Fujiwara, S., Akahoshi, M., Neriishi, K., Wong, T.Y., Kiuchi, Y., 2014. Is the association between smoking and the retinal venular diameter reversible following smoking cessation? Invest. Ophthalmol. Vis. Sci. 55 (1), 405-411.

Young, R.C., Biggs, J.T., Ziegler, V.E., Meyer, D.A., 1978. A rating scale for mania: reliability, validity and sensitivity. Br. J. Psychiatry 133, 429-435.

Zenteno, J.C., Crespi, J., Buentello-Volante, B., Buil, J.A., Bassaganyas, F., VelaSegarra, J.I., Diaz-Cascajosa, J., Marieges, M.T., 2014. Next generation sequencing uncovers a missense mutation in COL4A1 as the cause of familial retinal arteriolar tortuosity. Graefe's Archive for Clinical and Experimental Ophthalmology = Albrecht von Graefes Archiv fur klinische und experimentelle Ophthalmologie 252 (11), 1789-1794. 